\title{
Development of Real-Time Measurement of Salinity Concentration to Evaluate Suitable Food Dipping States During Salting
}

\author{
Kyoko ISHIKAWA*, Masashi NAKO*, Shuya SATO* and Yoshinobu AKIYAMA* \\ * Department of Biotechnology, Faculty of Bioresource Sciences, Akita Prefectural University, \\ 241-438 Kaidobata Nishi, Shimoshinjo Nakano, Akita 010-0195, Japan \\ E-mail:kyoko_ishikawa@akita-pu.ac.jp
}

\begin{abstract}
For this study, we developed a novel real-time monitoring system using a stainless steel electrode to assess $\mathrm{NaCl}$ osmosis in the food interior by measuring electrical impedance. The $\mathrm{NaCl}$ penetration into agar gel sprayed with $\mathrm{NaCl}$ on the surface was evaluated using impedance. As the measured position of the electrode moves downward, a longer time is needed to obtain a constant impedance value. Measurement of the chloride concentrations in the model food that had been cut into four pieces (surface, upper, middle, and lower parts) revealed an extremely strong relation between the equilibrium period of the impedance value and the inner chloride concentrations of the model. Results confirmed that a similar impedance value was obtained if the concentration of $\mathrm{NaCl}$ sprinkled on the top of the gels was the same irrespective of points measured using the electrode. These results demonstrate that this impedance measurement method using an LCR meter is useful for real-time monitoring of $\mathrm{NaCl}$ osmosis in the food interior.
\end{abstract}

Keywords : Penetration, Real-time measurement, Salting process

\section{INTRODUCTION}

Salt, $\mathrm{NaCl}$, a fundamentally important seasoning for cooking, affects not only the taste of dishes but also the texture of food because of dehydration and tightening of meat and fish through denaturation of their proteins ${ }^{1-4)}$. Nevertheless, excessive $\mathrm{NaCl}$ intake causes disease. For that reason, reduction of $\mathrm{NaCl}$ intake is often recommended ${ }^{5}$. Heretofore, $\mathrm{NaCl}$ contents in food have been ascertained through analyses of constituents of water extracted from food materials. However, according to this procedure, the penetration of $\mathrm{NaCl}$ into the food interior cannot be evaluated in real time. Based on past experience, one might dip foods into $\mathrm{NaCl}$ for a long period, thereby leading to excessive $\mathrm{NaCl}$ intake. For this study, we used a stainless steel electrode to measure electrical impedance. Thereby, we developed a novel real-time monitoring system for $\mathrm{NaCl}$ osmosis in the food interior.

\section{MATERIALS AND METHODS}

\subsection{Model food preparation}

Two gels made from agar and egg white were used as model foods. To prepare the agar gel, agar powder (Kanten Cook; Ina Food Industry Co. Ltd.) was added to distilled water at $0.8 \%$ (w/ w) concentration. It was then dissolved by boiling. The solution $(25 \mathrm{~g})$ was solidified in a glass case (length $25 \mathrm{~mm} \times$ width $25 \mathrm{~mm}$ $\times$ height $50 \mathrm{~mm}$ ) and was stored for $30 \mathrm{~min}$ at room temperature $\left(25^{\circ} \mathrm{C}\right.$ ). Egg white powder (dried albumen K type; Kewpie Egg Corp.) was stirred for $30 \mathrm{~min}$ in distilled water at $7.5 \%(\mathrm{w} / \mathrm{w})$ concentration. After filtration through a tea strainer, the filtrate $(25 \mathrm{~g})$ was poured into a glass case $(25 \mathrm{~mm} \times 25 \mathrm{~mm} \times 50 \mathrm{~mm})$. After covering the top of the case, the egg white solution was heated in a boiling steamer for $10 \mathrm{~min}$ and was steamed in a pan for another $30 \mathrm{~min}$. Subsequently, it was solidified by cooling at room temperature for $30 \mathrm{~min}$. All gels $(25 \mathrm{~mm} \times 25 \mathrm{~mm} \times 35 \mathrm{~mm})$ were used for measurement while they were still in the glass case.

\subsection{Impedance measurement}

The stainless steel rod electrodes that had been film-coated by insulating spray were inserted into the food interior to measure the impedance of the surface, upper, middle, and the lower regions of the food (Figure 1). After sprinkling various amounts of $\mathrm{NaCl}$ all over the gel surfaces, the impedance values of gels were measured using an Inductance Capacitance and Residence (LCR) meter (3523-50; Hioki E. E. Corp., Japan). The sample impedance

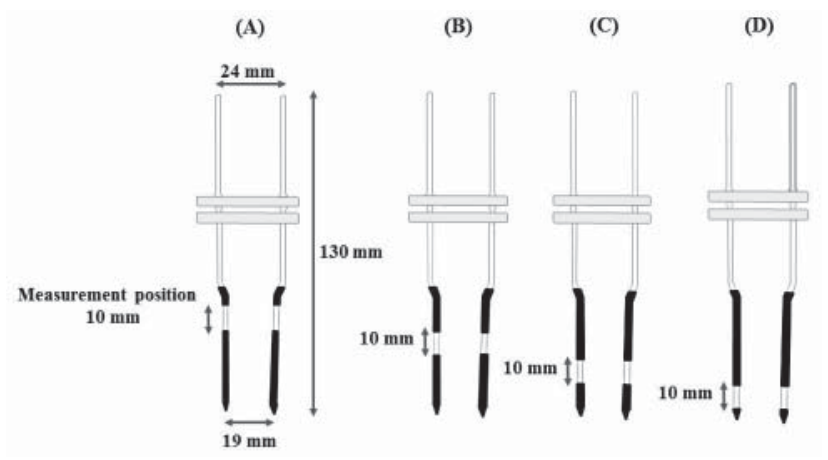

Figure 1 Stainless steel stick electrode used for impedance measurement. Insulation spray coated onto electrodes for measurement of the impedance value of part of foods: A, surface electrode; B, upper position electrode; $\mathrm{C}$, middle position electrode; $\mathrm{D}$, lower position electrode. 


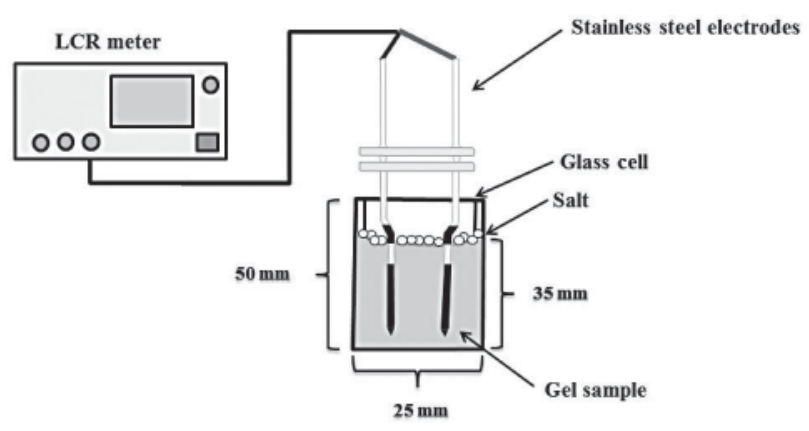

Figure 2 Schematic diagram showing the experimental apparatus for measurement of impedance by an LCR meter.

was measured at a frequency of $1 \mathrm{kHz}$ at $1 \mathrm{~V}$. Figure 2 portrays a schematic diagram of experimental apparatus used for the measurement of impedance by an LCR meter. When salt dissolves in the food surface and penetrates into the interior, the impedance value decreases gradually. Because $\mathrm{NaCl}$ penetrates into food and gradually diffuses, the impedance value keeps decreasing, but after a certain time the amount of change becomes negligible. We investigated the time within which the change amount is within 1 and set the measurement time. The results of the impedance measurement up to $1200 \mathrm{~s}$ after spraying $0.5 \mathrm{~g} \mathrm{NaCl}$ on the agar surface are taken as an example. Results show that the impedance value at $900 \mathrm{~s}$ was $184.0( \pm 42.2)$. The impedance value at $1200 \mathrm{~s}$ was $180.3( \pm 40.4)$. These differences were comparable to the differences found between samples. We thought that no problem existed. Therefore, the measurement time was set as follows. After sprinkling $0.5 \mathrm{~g}$ of $\mathrm{NaCl}$ on the gel surface, impedance values after $15 \mathrm{~min}$ for the surface electrode, $40 \mathrm{~min}$ for the upper electrode, and $75 \mathrm{~min}$ for the middle electrode were obtained. Similarly, for the $1.0 \mathrm{~g}$ and $2.0 \mathrm{~g} \mathrm{NaCl}$, the impedance value was set to $15 \mathrm{~min}$ for the surface electrode, $60 \mathrm{~min}$ for the upper electrode, and $120 \mathrm{~min}$ for the middle electrode. After allowing the $\mathrm{NaCl}$ to permeate for a given time, the $\mathrm{NaCl}$ remaining on the surface of the agar gel was flushed with distilled water on a Petri dish. After the gels were cut into pieces at each electrode height, the chloride ion concentration was ascertained $^{6,7)}$. The obtained measured values were converted to the $\mathrm{NaCl}$ amount. After the washed $\mathrm{NaCl}$ on the Petri dish was heated on a hot plate, the weight was measured as dry solid $\mathrm{NaCl}$ by evaporating the water.

\subsection{Food salinity measurement using impedance}

We prepared four agar gels containing 1.0, 3.0, 5.0, 7.0, 9.0, and $11 \%$ of $\mathrm{NaCl}(\mathrm{w} / \mathrm{v})$ at the measurement position to ascertain the inner concentrations of $\mathrm{NaCl}$ in the gels (Figure 3 ). The impedance value after $40 \mathrm{~min}$ was measured. The impedance value of each

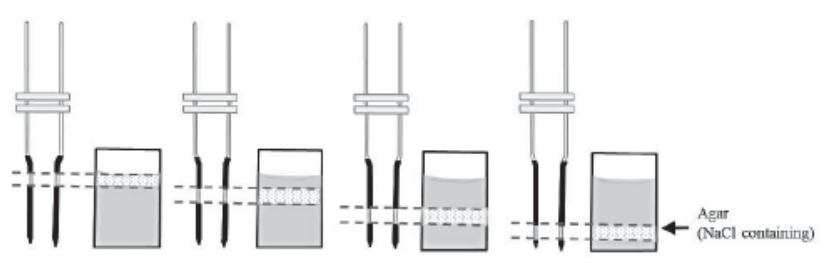

Figure 3 Schematic diagram showing the agar containing part of $\mathrm{NaCl}$ and the electrode position. part was compared at the same concentration.

\section{RESULTS AND DISCUSSION}

A high $\mathrm{NaCl}$ concentration is set in this study because, reportedly, $\mathrm{NaCl}$ is sprinkled on the surface with $12-18 \%$ against plum when making pickles ${ }^{8}, 2-18 \%$ for vegetables when preparing pickles $^{9)}$, and $7 \%$ for fish when making dried fish ${ }^{10)}$. Therefore, at the start of processing, $\mathrm{NaCl}$ does not dissolve but instead exists as a layer on the food surface. In this experiment, to model the actual process of food processing, $0.5,1.0$, and $2.0 \mathrm{~g}$ were sprinkled on the agar gel surface so that $\mathrm{NaCl}$ remained on the agar gel surface even after the impedance measurement was completed.

When $\mathrm{NaCl}$ is sprinkled on the food surface, it dissolves into the moisture on the surface of food, which becomes saline; thereafter, it gradually penetrates into food. At that time, the electric resistance decreases, but it varies gradually. We studied how $\mathrm{NaCl}$ is dissolved on the food surface by measuring the change of the impedance value on the gel surface using an LCR meter ${ }^{11)}$. The impedance value for $900 \mathrm{~s}$ after adding $\mathrm{NaCl}$ to the agar gel surface was almost equal to that with addition of 0.5 and $1.0 \mathrm{~g}$ salt, but the impedance value with $2.0 \mathrm{~g}$ salt was lower than the others (Figure 4). These results suggest that the amount of added $\mathrm{NaCl}$ affects the impedance values at the gel surface.

Figure 5 presents impedance values associated with the penetration of the $\mathrm{NaCl}$ in the agar gel after sprinkling different amounts of $\mathrm{NaCl}$ to the agar gel. Furthermore, the length of time during which the same impedance value is indicated as the standard deviation. When sprinkling $\mathrm{NaCl}$ on the food surface, the impedance value decreases gradually. The impedance on the gel surface became almost constant after $15 \mathrm{~min}$, irrespective of the added $\mathrm{NaCl}$ amount. The impedance at the upper site of 1.0 and $2.0 \mathrm{~g} \mathrm{NaCl}$ addition reached nearly constant after $60 \mathrm{~min}$. However, with the addition of $0.5 \mathrm{~g}$ of $\mathrm{NaCl}$, a nearly constant value was obtained after $40 \mathrm{~min}$. With 1.0 and $2.0 \mathrm{~g}$ salt addition to the middle site, the impedance value was obtained as an almost constant value after $120 \mathrm{~min}$. In the case of adding $0.5 \mathrm{~g}$ of salt, a constant value was obtained after $75 \mathrm{~min}$. Results indicate that the time necessary for the impedance value of the middle site to stabilize is twice that of the upper site. The equilibration time with $0.5 \mathrm{~g}$ of $\mathrm{NaCl}$ addition was probably short because the small amount of salt was dissolved

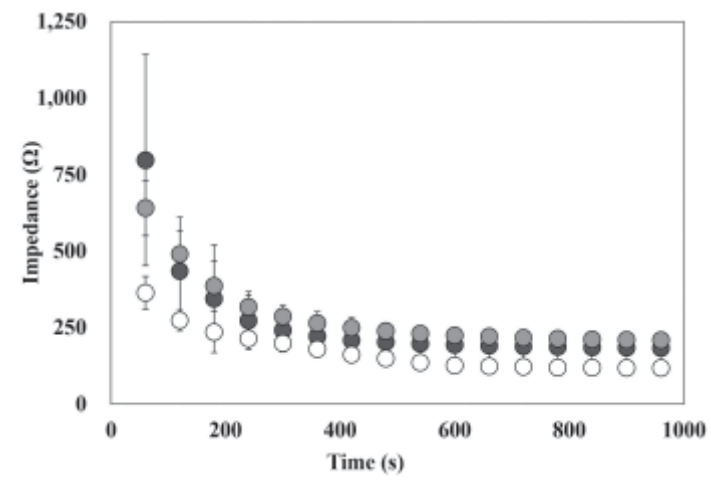

Figure 4 Impedance values after addition of 0.5-2.0 g NaCl were measured at the gel surface:

, impedance after $0.5 \mathrm{~g} \mathrm{NaCl}$ added to the agar surface;

$\mathrm{O}$, impedance after $1.0 \mathrm{~g} \mathrm{NaCl}$ added to the agar surface;

$\mathrm{O}$, impedance after $2.0 \mathrm{~g} \mathrm{NaCl}$ added to the agar surface. 


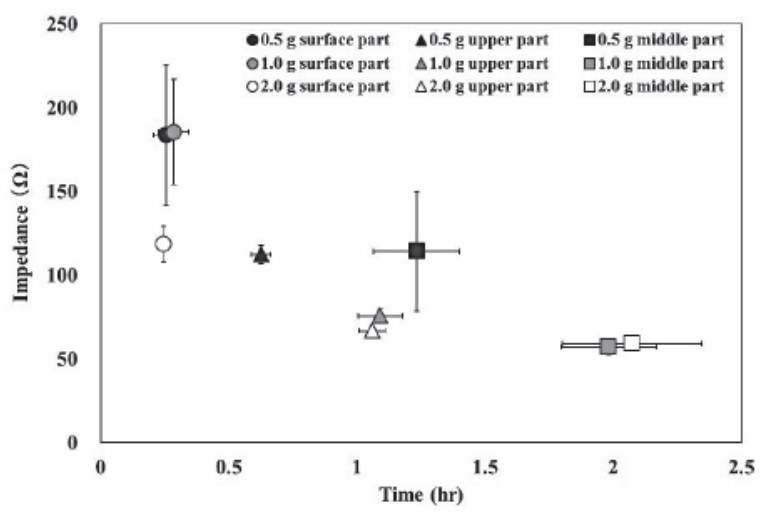

Figure 5 Changes of impedance with various amounts of added $\mathrm{NaCl}$ at different measurement positions.

Impedance values after addition of $0.5-2.0 \mathrm{~g} \mathrm{NaCl}$ were measured at four locations of gels: surface, upper, middle, and bottom.

easily and diffused quickly to the agar. It was impossible to obtain a stable impedance value in the lower site. This behavior must be different from the diffusion mechanism of $\mathrm{NaCl}$ at the upper and middle site.

Impedance values on the upper part after addition of $0.5,1.0$, and $2.0 \mathrm{~g}$ of $\mathrm{NaCl}$ on top of agar gels were, respectively, 112, 76, and $67 \Omega$ (Figure 5). Impedance is an electrical resistance value that has negative correlation to the penetration amount of $\mathrm{NaCl}$. Therefore, the addition of $0.5 \mathrm{~g}$ of $\mathrm{NaCl}$ showed the highest impedance value obtained in the study.

Impedance values on the middle part after addition of $0.5,1.0$, and $2.0 \mathrm{~g}$ of $\mathrm{NaCl}$ on top of agar gels were, respectively, 114, 57, and $59 \Omega$ (Figure 5). In the experiment using the middle electrode, the impedance values obtained by adding $1.0 \mathrm{~g}$ and $2.0 \mathrm{~g}$ of $\mathrm{NaCl}$ to the agar surface were equal. Because these impedance values are approximately equal values of about $50 \Omega$, the internal $\mathrm{NaCl}$ concentration might be saturated. However, the impedance value obtained by adding $0.5 \mathrm{~g}$ of $\mathrm{NaCl}$ to the agar surface was about $100 \Omega$ at both the upper and the middle electrode, which suggests that $0.5 \mathrm{~g}$ of $\mathrm{NaCl}$ had an insufficient amount of $\mathrm{NaCl}$ to penetrate to the middle electrode.

Additionally, we succeeded in visualizing the penetration behavior of $\mathrm{NaCl}$ into agar gel by spraying $\mathrm{NaCl}$ on the surface of agar gel containing silver nitrate ${ }^{12}$. Results confirmed that electrical impedance measurement is a useful tool to monitor $\mathrm{NaCl}$ penetration.

Subsequently, we examined the correlation between the impedance value of the agar gel and the $\mathrm{NaCl}$ concentration. $\mathrm{NaCl}$ was allowed to penetrate the food until the equilibrium time of each electrode. Then the agar was cut at the position of the electrode. After the salinity concentrations of each agar were measured, the amount of $\mathrm{NaCl}$ per $25 \mathrm{~g}$ of agar was calculated (Figure 6). The amount of $\mathrm{NaCl}$ remaining on the agar gel surface is portrayed in Figure 7. The amounts of $\mathrm{NaCl}$ at the agar gel surface were $0.11 \mathrm{~g}$ (addition of $0.5 \mathrm{~g}$ of $\mathrm{NaCl}), 0.15 \mathrm{~g}(1.0 \mathrm{~g})$, and $0.15 \mathrm{~g}(2.0 \mathrm{~g})$ at the equilibrium time on the surface part electrode. Amounts of $\mathrm{NaCl}$ at the upper position of agar gel were $0.05 \mathrm{~g}$ (addition of $0.5 \mathrm{~g}$ of $\mathrm{NaCl}), 0.20 \mathrm{~g}(1.0 \mathrm{~g})$, and $0.23 \mathrm{~g}(2.0 \mathrm{~g})$ at the equilibrium time on the upper electrode. Amounts of $\mathrm{NaCl}$ at the middle position of agar gel were $0.03 \mathrm{~g}$ (addition of $0.5 \mathrm{~g}$ of $\mathrm{NaCl}), 0.05 \mathrm{~g}(1.0 \mathrm{~g})$,
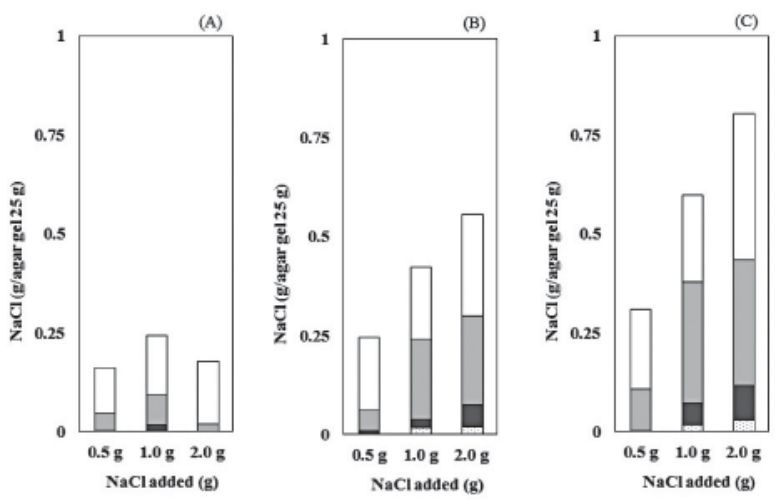

Figure $6 \mathrm{NaCl}$ concentrations of agar gels.

Following the sprinkling of various amounts of $\mathrm{NaCl}$ on the agar surface, the agar gels were incubated by reaching equilibrium time at the surface (A), upper (B), and middle (C) electrodes. Gels were cut into four pieces: surface (white), upper (light gray), middle (dark gray), and lower parts (dotted); the $\mathrm{NaCl}$ concentrations were measured at surface, upper, middle, and lower positions.
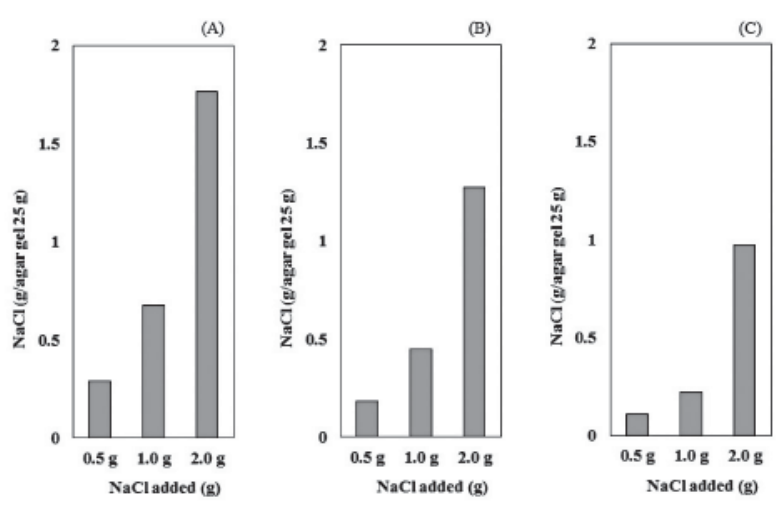

Figure 7 Remaining amounts of $\mathrm{NaCl}$ on the agar gel surface.

Following the sprinkling of various amounts of $\mathrm{NaCl}$ on the agar surface, the agar gels were incubated by reaching equilibrium time at the surface (A), upper (B), and middle (C) electrodes.

and $0.09 \mathrm{~g}(2.0 \mathrm{~g})$ at the equilibrium time on the middle electrode. These results demonstrate that the amounts of $\mathrm{NaCl}$ on three electrodes by addition of $0.5 \mathrm{~g}$ were lower than those by addition of $1.0 \mathrm{~g}$ or $2.0 \mathrm{~g}$ of $\mathrm{NaCl}$. The results agree with the impedance value. The total $\mathrm{NaCl}$ concentrations (the sum of the surface, upper, middle, and lower parts) were compared at each equilibrium time. By addition of 1.0 and $2.0 \mathrm{~g}$ of $\mathrm{NaCl}$ to the agar gel, the amount of $\mathrm{NaCl}$ increased as time passed, but $0.5 \mathrm{~g} \mathrm{NaCl}$ increased only slightly. As the penetration time increased, the amount of $\mathrm{NaCl}$ remaining on the food surface decreased (Figure 7). Results show that the relation between amount of $\mathrm{NaCl}$ in the agar gel and the electrical impedance measurement is high.

We also measured the penetration behavior of $\mathrm{NaCl}$ on egg white gel. The equilibrium time increased along with the measured points of the electrode from the upper part of the gel to the lower part. Furthermore, a close relation was found between the chloride ion concentration and electrical impedance. The method described herein is applicable not only to agar gel, but also to other gels.

We prepared an agar gel containing $\mathrm{NaCl}(1.0,3.0,5.0,7.0$, 9.0, 


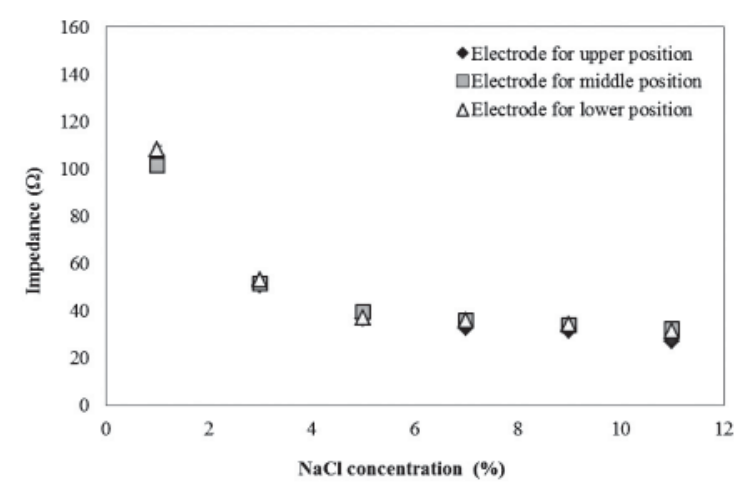

Figure 8 Impedance in agar gels with various concentrations of $\mathrm{NaCl}$. We prepared agar gels containing $\mathrm{NaCl}$ of 1.0, 3.0, 5.0, 7.0, 9.0, and $11 \%$, respectively, at upper, middle, and lower electrode contact positions. The impedance of the gel at each position was measured after $40 \mathrm{~min}$.

and $11 \%$ ) for which upper, middle, and lower positions contact with an electrode. The impedance value of the gel was measured at each position. To evaluate the impedance values inside the food, only the results of the upper electrode, the intermediate electrode, and the lower electrode are presented in Figure 8. Results show that impedance values depend on the $\mathrm{NaCl}$ concentration, but not on the measurement position. As the $\mathrm{NaCl}$ concentration increased, the impedance value decreased gradually. However, when the $\mathrm{NaCl}$ concentration was higher than $5 \%$, the change in the impedance value became small. Although the measurement methods were somewhat different, we tried to take measurements when saline having a concentration of $1.0-26 \%$ was added to the surface of the $\operatorname{agar}_{\text {gel }}^{13)}$.

Even in that case, the difference in impedance values was as slight as $15-26 \%$. The results suggest that the electrical impedance method can evaluate the $\mathrm{NaCl}$ concentration in model foods with $\mathrm{NaCl}$ concentration up to $7 \%$. According to the food ingredient table, the $\mathrm{NaCl}$ equivalent amount in food is $4.3 \%$ for turnip and radish pickles and 0.9 to $6.1 \%$ for dried fish ${ }^{14)}$. The impedance method is regarded as usable for this processing, which uses much $\mathrm{NaCl}$. However, the $\mathrm{NaCl}$ equivalent amount of the plum pickle was $19.3 \%{ }^{14}$. Furthermore, it is important to construct a system that can quantify high-salinity foods such as plums. In conclusion, results demonstrate that our impedance measurement method using the LCR meter can monitor $\mathrm{NaCl}$ penetration in the food interior in real time, even at a low $\mathrm{NaCl}$ concentration range.

\section{Acknowledgements}

This work was supported by JSPS KAKENHI Grant Numbers JP 21700741 and JP 26350096.

\section{References}

[1] Ohtsubo, F.; Miyagawa, K., "Dehydration of Vegetables in Saline Solutions" Bull. Soc. Sea Water Sci. Jpn. 44, 328-333 (1990) (in Japanese).

[2] Makabe, Y., "Presumption for Ending the Soaking of Vegetable Using Sodium Chloride Concentration in Vegetables" Bull. Soc. Sea Water Sci. Jpn. 65, 42-46 (2011) (in Japanese).

[3] Tanaka, M., "Functions and Roles of Salt in Processing and Preservation of Foods" Bull. Soc. Sea Water Sci. Jpn. 52, 352358 (1998) (in Japanese).

[4] Arai, K., "Denaturation of muscular proteins from marine animals and its control" Nippon Suisan Gakkaishi, 62, 137143 (2002) (in Japanese).

[5] Kurimori, S., "Dietary habits improvement by which aims at low salt in Akita prefecture" J. Integr. Stud. Diet. Habits 19, 99-106 (2008) (in Japanese).

[6] "Sionobunsekitobusseisokutei" Bulletin of the Society of Sea Water Science, Japan and The Salt Science Research Foundation, pp.332-335 (1992) (in Japanese).

[7] Ishikawa, K.; Tsukidate, A., "Influence of Crystal Particle Size of Salt on Food Taste and Texture" Bull. Soc. Sea Water Sci. Jpn. 67, 340-344 (2013) (in Japanese).

[8] Nakayama, Y.; Hasegawa, M., "Study of a Method to Control the Amount of Sodium Chloride and Citric Acid in Pickled Fruit Products" Bull. Soc. Sea Water Sci. Jpn. 67, 202-207 (2013) (in Japanese).

[9] Miyao, S., "Japanese Pickling Vegetables "Tsukemono" " Bull. Soc. Sea Water Sci. Jpn. 71, 211-221 (2017) (in Japanese).

[10] Shimosaka, C; Ishida, Y.; Shimomura, M., "Effect of Dry Salting Method and Brine Salting Method on Texture of Salted Dried Horse Mackerel" Journal of Family Issues 41, 1159-1167 (1990) (in Japanese).

[11] Ishikawa, K.; Tsukidate, A.; Suzuki, M.; Sugawara, H.; Akiyama, Y., "Measurement System for Solubility and Osmosis of Salt in Food" Int. J. Soc. Mate. Eng. Resour. 20, 154-157 (2014).

[12] Reported elsewhere.

[13] Unpublished data.

[14] Food Composition Database, Ministry of Education, Sports, Science and Technology (https://fooddb.mext.go.jp) (accessed 2018.6.1) 